\title{
Synthesis of steel slag ceramics: chemical composition and crystalline phases of raw materials
}

\author{
Li-hua Zhao ${ }^{1,2)}$,Wei Wei ${ }^{1,2)}$, Hao Bai ${ }^{1,2)}$, Xu Zhang $^{1,2)}$, and Da-qiang Cang ${ }^{1,2)}$ \\ 1) School of Metallurgical and Ecological Engineering, University of Science and Technology Beijing, Beijing 100083, China \\ 2) State Key Laboratory of Advanced Metallurgy, University of Science and Technology Beijing, Beijing 100083, China \\ (Received: 23 September 2014; revised: 4 November 2014; accepted: 5 November 2014)
}

\begin{abstract}
Two types of porcelain tiles with steel slag as the main raw material (steel slag ceramics) were synthesized based on the $\mathrm{CaO}-\mathrm{Al}_{2} \mathrm{O}_{3}-\mathrm{SiO}_{2}$ and $\mathrm{CaO}-\mathrm{MgO}-\mathrm{SiO}_{2}$ systems, and their bending strengths up to $53.47 \mathrm{MPa}$ and $99.84 \mathrm{MPa}$, respectively, were obtained. The presence of anorthite, $\alpha$-quartz, magnetite, and pyroxene crystals (augite and diopside) in the steel slag ceramics were very different from the composition of traditional ceramics. X-ray diffraction (XRD) and electron probe X-ray microanalysis (EPMA) results illustrated that the addition of steel slag reduced the temperature of extensive liquid generation and further decreased the firing temperature. The considerable contents of glass-modifying oxide liquids with rather low viscosities at high temperature in the steel slag ceramic adobes promoted element diffusion and crystallization. The results of this study demonstrated a new approach for extensive and effective recycling of steel slag.
\end{abstract}

Keywords: ceramic materials; synthesis; steel slag; chemical composition; crystalline phases; solid waste recycling

\section{Introduction}

Steel slag, which consists of the metallic oxides produced in the course of refining, corroded brasque materials, impurities due to metallic charge, and slag-making materials for the modification of steel slag, is the main solid waste in the steel-making process [1]. According to statistical data, steel output in China reached $7.5 \times 10^{8} \mathrm{t}$ in 2013 , and the amount of steel slag discharge was about $9.0 \times 10^{7} \mathrm{t}$ [2]. With the increase in crude steel production, the recycling of steel slag has become more significant; however, the current rate of steel slag recycling in China is only $10 \%$ since the steel slag contains free calcium oxide ( $\mathrm{f}-\mathrm{CaO})$ and free magnesia oxide (f-MgO) [3], which make slag reuse difficult. In general, due to its specific chemical composition and crystal phase, steel slag is used to make road construction materials, cement, and concrete additives. However, more novel approaches are being developed for the efficient use of steel slag as agricultural fertilizers, ameliorants of acid soil, glass-ceramics, and porcelain tiles. Despite these efforts, the utilization of steel slag is still limited, and the added value of the recycled products remains low. Thus, studies on these technologies are significant for the development of a circular economy and to increase the utilization efficiency of metallurgical resources in China.

The chemical composition of steel slag contains $\mathrm{Si}, \mathrm{Ca}$, $\mathrm{Mg}, \mathrm{Fe}$, and $\mathrm{Al}$, and the normal crystal phases are dicalcium silicate, calcium ferrite, hematite, and magnetite. The raw materials of traditional porcelain tiles are generally natural minerals such as clay, feldspar, and quartz. Due to the similarities in chemical composition between porcelain tiles and steel slag, steel slag can act as a raw material for ceramics. Many exploratory reports in China come from Wuhan University of Technology [4-5], and the steel slag ceramic products include building blocks and porcelain floor tiles. As an overburning melt with low softening temperature and homogenous phases, steel slag promotes liquid phase generation at low temperature and accelerates the firing process when it is used to make ceramics; therefore, the addition of steel slag can decrease the firing temperature and time, which is conducive to energy conservation and emission 
reductions for the ceramic industry.

The chemical compositions of traditional porcelain tiles produced with clay minerals as the main raw materials are $\mathrm{Si}, \mathrm{Al}, \mathrm{K}$, and $\mathrm{Na}$, and they seldom contain amorphous phases. In contrast, some features of steel slag differ from those of clay; the content of $\mathrm{Al}_{2} \mathrm{O}_{3}$ in steel slag is rather low, while $\mathrm{CaO}, \mathrm{MgO}$, and iron oxides are plentiful (especially in basic slag). Due to the water quenching treatment of steel slag, active glassy phases are abundant, which is also obviously different from clay. Due to the difference in chemical composition between steel slag and clay minerals, the $\mathrm{Al}_{2} \mathrm{O}_{3}-\mathrm{SiO}_{2}$ system of traditional ceramics may not be suitable for the steel slag ceramics. The chemical composition of steel slag belongs to the $\mathrm{CaO}-\mathrm{MgO}-\mathrm{Al}_{2} \mathrm{O}_{3}-\mathrm{SiO}_{2}$ system, which can be divided into two subsystems $\left(\mathrm{CaO}-\mathrm{Al}_{2} \mathrm{O}_{3}-\mathrm{SiO}_{2}\right.$ and $\mathrm{CaO}-\mathrm{MgO}-\mathrm{SiO}_{2}$ ) based on the contents of $\mathrm{Al}_{2} \mathrm{O}_{3}$ and $\mathrm{MgO}$. The main crystal phases of the $\mathrm{CaO}-\mathrm{Al}_{2} \mathrm{O}_{3}-\mathrm{SiO}_{2}$ system are anorthite, gehlenite, and mullite, while those of the $\mathrm{CaO}-\mathrm{MgO}-\mathrm{SiO}_{2}$ system are diopside, akermanite, and forsterite. To date, research has focused on the synthesis of steel slag glass-ceramics because anorthite possesses a good (low) coefficient of thermal expansion, and the existence of diopside enhances the wear resistance and bending strength, which are important indicators of ceramic performance, especially for porcelain tiles.

This study focuses on the synthesis of steel slag porcelain tiles based on the formulae of different silicate systems. Thus, the sintering, vitrification, and crystallization processes were analyzed on the microscale, and the feasibility of using steel slag as a raw material for ceramic production was discussed.

\section{Raw materials and methods}

\subsection{Raw materials and formula design}

Since steel slag has poor plasticity after cooling; if slag is used as the raw material for ceramic production, a proper clay (kaolin, pyrophyllite, etc.) should be added to improve the formability and firing performance.

To obtain efficient slag utilization, the content of steel slag in this study was more than $30 \mathrm{wt} \%$. The clays used included kaolin, pyrophyllite, fired talc, and potash feldspar. According to the contents of $\mathrm{Al}_{2} \mathrm{O}_{3}$ and $\mathrm{MgO}$, the formulae can be classified as either the $\mathrm{CaO}-\mathrm{Al}_{2} \mathrm{O}_{3}-\mathrm{SiO}_{2}$ system (A) or the $\mathrm{CaO}-\mathrm{MgO}-\mathrm{SiO}_{2}$ system (M). Two different kinds of steel slag (slag 1 and slag 2) were utilized in the experiments; their compositions are shown in Table 1. Due to the low $\mathrm{MgO}$ content of steel slag, roasted talcum was added as the main source of $\mathrm{Mg}$, which can adjust the composite point of the formula to the diopside crystalline region in the $\mathrm{CaO}-\mathrm{MgO}-\mathrm{SiO}_{2}$ system phase diagram. The firing process was conducted in a typical Chinese ceramic factory, and the formulae are shown in Table 2.

Table 1. Compositions of the steel slags utilized as raw materials for ceramic production

\begin{tabular}{ccccccccccc}
\hline Steel slag & $\mathrm{SiO}_{2}$ & $\mathrm{Al}_{2} \mathrm{O}_{3}$ & $\mathrm{MgO}$ & $\mathrm{CaO}$ & $\mathrm{TiO}_{2}$ & $\mathrm{Fe}_{2} \mathrm{O}_{3}$ & $\mathrm{~K}_{2} \mathrm{O}$ & $\mathrm{Na}_{2} \mathrm{O}$ & I.L. $^{\mathrm{a}}$ & $\mathrm{Sum}$ \\
\hline Slag 1 & 31.54 & 8.86 & 7.27 & 1.19 & 36.23 & 8.98 & 0.08 & 0.12 & 0.26 & 94.53 \\
Slag 2 & 14.42 & 2.64 & 20.01 & 0.18 & 42.71 & 6.74 & 0.16 & 0.25 & 3.91 & 91.02 \\
\hline
\end{tabular}

Note: ${ }^{a}$ I.L.- Ignition loss.

Table 2. Formulae of the $\mathrm{CaO}-\mathrm{Al}_{2} \mathrm{O}_{3}-\mathrm{SiO}_{2}$ and $\mathrm{CaO}-\mathrm{MgO}-\mathrm{SiO}_{2}$ systems (represented by oxides)

\begin{tabular}{|c|c|c|c|c|c|c|c|c|c|c|c|}
\hline \multirow{2}{*}{ System } & \multirow{2}{*}{$\begin{array}{c}\text { Formula } \\
\text { No. }\end{array}$} & \multicolumn{9}{|c|}{ Composition / wt $\%$} & \multirow{2}{*}{$\begin{array}{c}\text { Firing tempera- } \\
\text { ture } /{ }^{\circ} \mathrm{C}\end{array}$} \\
\hline & & $\mathrm{SiO}_{2}$ & $\mathrm{Al}_{2} \mathrm{O}_{3}$ & $\mathrm{MgO}$ & $\mathrm{CaO}$ & $\mathrm{TiO}_{2}$ & $\mathrm{Fe}_{2} \mathrm{O}_{3}$ & $\mathrm{~K}_{2} \mathrm{O}$ & $\mathrm{Na}_{2} \mathrm{O}$ & Sum & \\
\hline \multirow{3}{*}{ A } & A1 & 48.48 & 18.12 & 3.07 & 12.32 & 0.48 & 2.93 & 1.70 & 0.04 & 87.14 & 1230 \\
\hline & $\mathrm{A} 2$ & 53.72 & 14.99 & 4.26 & 13.18 & 0.51 & 2.93 & 0.71 & 0.04 & 90.35 & 1125 \\
\hline & A3 & 57.28 & 17.33 & 2.33 & 9.06 & 0.40 & 2.20 & 0.84 & 0.04 & 89.49 & 1125 \\
\hline \multirow{3}{*}{ M } & M1 & 45.19 & 6.02 & 11.44 & 18.38 & 0.15 & 8.23 & 0.43 & 0.10 & 89.92 & 1220 \\
\hline & M2 & 45.51 & 6.02 & 11.20 & 18.35 & 0.15 & 8.23 & 0.42 & 0.10 & 89.98 & 1220 \\
\hline & M3 & 48.49 & 5.88 & 11.81 & 16.35 & 0.14 & 7.23 & 0.42 & 0.09 & 90.41 & 1220 \\
\hline
\end{tabular}

\subsection{Synthesis and testing of ceramic samples}

The firing process used for ceramic tiles was similar to that of normal porcelain tiles and is described as follows.

(1) Ball-milling and mixing. The total mass of raw materials was $400 \mathrm{~g}$, and mass percentage of each component of the raw materials was calculated. To every group of raw materials, $0.3 \mathrm{wt} \%$ sodium tripolyphosphate (STPP) and $0.1 \mathrm{wt} \%$ carboxymethyl cellulose sodium were added. The wet mixture (every $100 \mathrm{~g}$ solid raw materials with $50 \mathrm{~g}$ water added) was ball-milled for $8 \mathrm{~min}$ to obtain a slurry, and the sieve residue of the slurry was controlled within a limit 
of $0.2 \mathrm{wt} \%-0.8 w \mathrm{t} \%$.

(2) De-ironing. Preliminary tests demonstrated that the negative correlation between ferric oxide content and the softening temperature of steel slag increases firing difficulty; therefore, de-ironing was necessary in this study. A bar magnet was used to remove the magnetic metallic iron and magnetite directly from the slurry.

(3) Drying. A certain degree of drying was carried out to achieve a final moisture content of $6 \mathrm{wt} \%-7 \mathrm{wt} \%$ for adobe pressing.

(4) Pelletization and adobe pressing. After filtered by a 20-mesh screen, the dry powder was pelletized and pressed into $5 \mathrm{~cm} \times 10 \mathrm{~cm} \times 0.8 \mathrm{~cm}$ adobes (briquetting pressure was 6-8 MPa). The adobe samples were then dried for about $1 \mathrm{~h}$.

(5) Ceramic firing. The dried adobes were fired in an electric stove or kiln with a firing temperature of $1100-1250^{\circ} \mathrm{C}$ (Table 2) for about $1 \mathrm{~h}$.

In this study, the following techniques and apparatus were used. The crystallized phases were identified by X-ray diffraction (XRD; Mac Science. Co. Ltd. M21x, Cu K ${ }_{\alpha}$ radiation, Japan). Scanning electron microscopy (SEM; JEOL Ltd. JSM-6480LV, Japan) was used for microstructural observations of polished and etched (by immersion in $2 \mathrm{vol} \%$ HF solution for $30 \mathrm{~s}$ ) surfaces. The mechanical properties were evaluated by measuring the three-point bending strengths of rectangular samples of porcelain tiles $(20 \mathrm{~mm} \times$ $30 \mathrm{~mm} \times 20 \mathrm{~mm}$ ). The sintering, vitrification, and crystallization processes were observed by electron probe X-ray microanalysis (EPMA; JEOL JXA-8100, Japan).

\section{Results}

The results of the bending strength measurements in Table 3 show that the maximum bending strength of samples in the $\mathrm{CaO}-\mathrm{Al}_{2} \mathrm{O}_{3}-\mathrm{SiO}_{2}$ system is $53.47 \mathrm{MPa}$, while that of the $\mathrm{CaO}-\mathrm{MgO}-\mathrm{SiO}_{2}$ system is $99.84 \mathrm{MPa}$. This indicates that the ceramic tiles made from steel slag exhibited excellent performances (the China National Regulation states that the bending strength should be more than $35 \mathrm{MPa}$ ), demonstrating the feasibility of ceramic synthesis using steel slag.

Table 3. Bending strength of the samples

$\mathrm{MPa}$

\begin{tabular}{cccc}
\hline & \multicolumn{3}{c}{ Formula No. } \\
\cline { 2 - 4 } System & 1 & 2 & 3 \\
\hline A & 47.26 & 51.34 & 53.47 \\
M & 80.62 & 99.84 & 78.21 \\
\hline
\end{tabular}

\subsection{Crystal phases of steel slag ceramics (porcelain tiles)}

The composition of traditional porcelain tiles made from clay raw materials can be assigned to the $\mathrm{Al}_{2} \mathrm{O}_{3}-\mathrm{SiO}_{2}$ system [6]. Mullite is the only stable crystal phase in this system; hence, mullite is the most common crystal in normal porcelain tiles [7], as demonstrated by many relevant research papers [8-9]. As the composition of steel slag ceramic belongs to the $\mathrm{CaO}-\mathrm{Al}_{2} \mathrm{O}_{3}-\mathrm{SiO}_{2}$ system or the $\mathrm{CaO}-\mathrm{MgO}-\mathrm{SiO}_{2}$ system, the crystal phases are theoretically different from those in traditional ceramics. The corresponding phase diagrams of the steel slag ceramic compositional systems can be referred in slag Atlas [6]. XRD was then used to study the crystal phases of the ceramic samples (Fig. 1).

Fig. 1 demonstrates that the crystal phase composition of the $\mathrm{CaO}-\mathrm{Al}_{2} \mathrm{O}_{3}-\mathrm{SiO}_{2}$ steel slag ceramic system is relatively complex. This system is dominated by crystal phases including anorthite, $\alpha$-quartz, and magnetite; meanwhile, a small quantity of pyroxene group crystals (augite and diopside) and enstatite are detected as well. Anorthite and pyroxene crystals are considered as newly generated crystal phases, while $\alpha$-quartz, magnetite, and roasted talcum are the crystal phases of the raw materials. This indicates that parts of the raw materials still exist after sintering. In contrast, the crystal phase composition of the $\mathrm{CaO}-\mathrm{MgO}-\mathrm{SiO}_{2}$ steel slag ceramic system is rather simple; it consists of augite, diopside, and pyroxene solid solution, all of which are newly generated crystal phases. The diffraction patterns of the raw materials disappeared completely, implying that the M-series samples experienced complete sintering, vitrification, and crystallization. It should be noted that due to the presence of $5 \mathrm{wt} \%-6 \mathrm{wt} \% \quad \mathrm{Al}_{2} \mathrm{O}_{3}$, the crystal phase composition of the M-series samples was close to that of the $\mathrm{CaO}-\mathrm{MgO}-\mathrm{Al}_{2} \mathrm{O}_{3}(5 \mathrm{wt} \%)-\mathrm{SiO}_{2}$ system [6]; however, the $\mathrm{CaO}-\mathrm{MgO}-\mathrm{SiO}_{2}$ system is discussed for convenience.

Based on the analysis of the XRD patterns, the crystal phases of the steel slag ceramics fit within the corresponding phase diagrams [6], which are significantly different from the phases of traditional ceramics. In fact, the difference between the crystal phases of the two ceramics stemming from the different compositions may also affect other characteristics, which will be discussed in sections 4.1 and 4.2.

\subsection{Sintering and vitrification in the firing process}

Ceramic production consists of the proportioning of raw materials, ball milling and mixing, pressing and modeling, drying, and firing. The processes of drying and firing can be termed heat treatment, while firing comprises sintering and vitrification. In ceramics manufacturing, the heat treatment 
results in a dense and coherent product that transforms from a porous and incompact state. In the sintering process, particles coalesce by solid-state diffusion at temperatures that are very high (e.g., $1200^{\circ} \mathrm{C}$ ) but below the melting point of the compound being sintered. Some ceramic products such as porcelain, clay bricks, and some electronic ceramics contain a glass phase. This glass phase serves as a reaction medium that allows diffusion to take place at a lower temperature

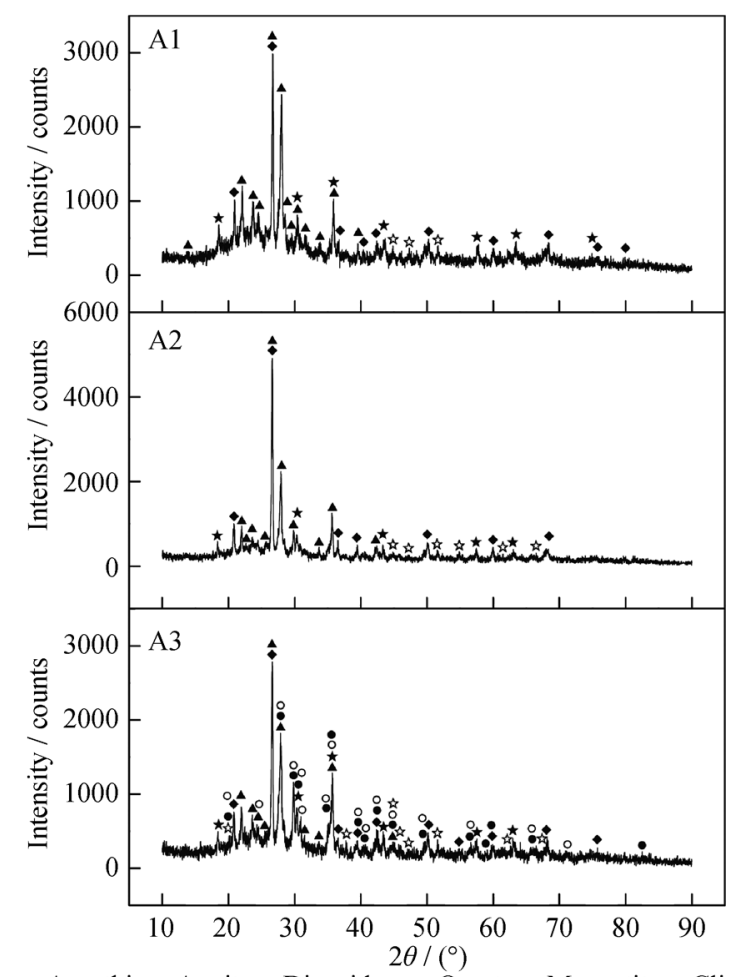

$\Delta$ Anorthic $\bullet$ Augite oDiopside $\bullet \alpha$-Quartz $\star$ Magnetite « Clinoenstatite

(a) A-series than in the rest of the ceramic solid material without glass phases. During the firing of these types of ceramic materials, a process called vitrification takes place; in this process, the glass phase is liquefied and fills the pore spaces of the material. This liquefied glass phase may also react with some of the remaining solid refractory materials. Upon cooling, the liquid phase solidifies to form a vitreous or glassy matrix that binds the un-melted particles together [6].

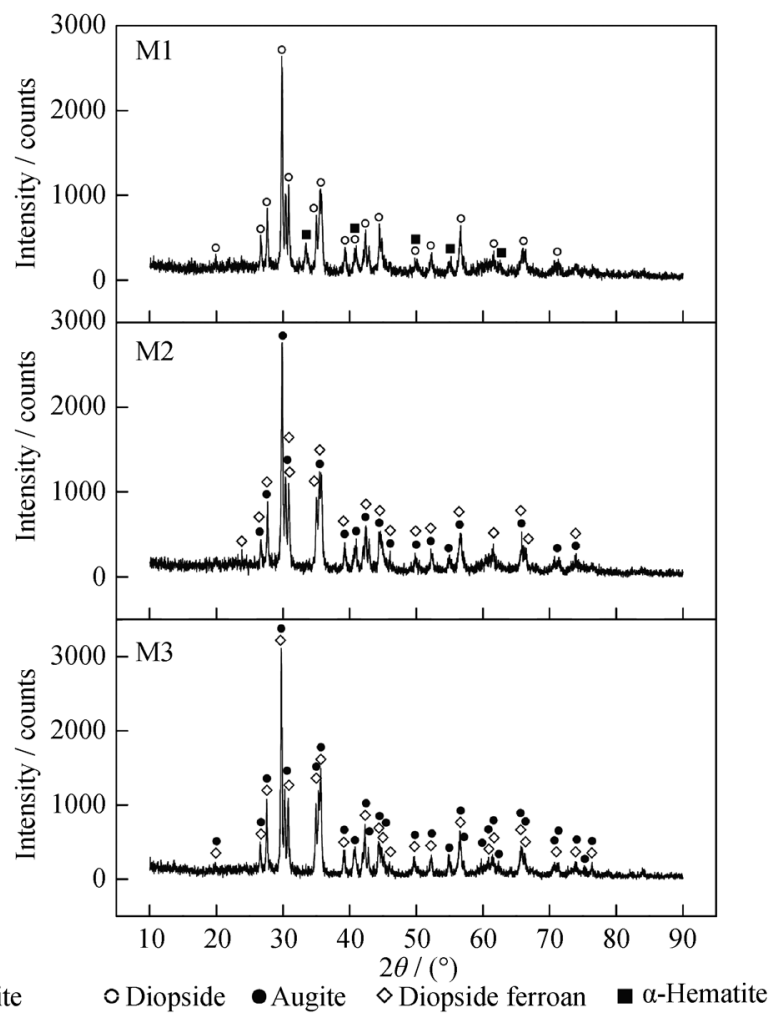

(b) M-series

Fig. 1. XRD patterns of A-series (a) and M-series (b) samples.

The diffusion of elements would happen in the processes of sintering and vitrification; hence, element diffusion can characterize the degree of sintering and vitrification. The element distribution and diffusion can be probed by EPMA.

EPMA was conducted on polished sample surfaces; the final stage of polishing employed $6.5-\mu \mathrm{m}$ abrasive paper. Typical surface micro districts on back scattering graphs were selected to scan the surface for $\mathrm{Fe}, \mathrm{Ca}, \mathrm{Al}, \mathrm{Mg}$, and $\mathrm{Si}$ because these elements were present in significant amounts in the samples.

The samples A3 and M2 were selected for EPMA. According to the backscattered images of the samples (Fig. 2), areas with similar gray scales displayed different sizes and shapes with no significant regularity for sample A3. In contrast, sample M2 exhibited analogous and inerratic areas with similar gray scales; the shapes of these areas were far different than the crushed particles of raw materials.

Due to the fact that the diffusion level reflects the sintering and vitrification process, surface element scanning was conducted to analyze $\mathrm{Fe}, \mathrm{Ca}, \mathrm{Al}, \mathrm{Mg}$, and $\mathrm{Si}$. The element distributions are shown in Fig. 3.

The district boundaries of the different phases and the significant element enrichment in sample A3 are depicted in Fig. 3(a); $\mathrm{Ca}$ and $\mathrm{Si}$ are particularly enriched, and the boundaries of Fe enrichment are distinct and irregular. Fig. 3(b) indicates significant element diffusion in sample M2 with inconspicuous element enrichment and fuzzy boundaries between phases, implying flowing liquid at high temperature. The distribution of $\mathrm{Si}$ was rather homogeneous in the probed micro-area of sample M2. 

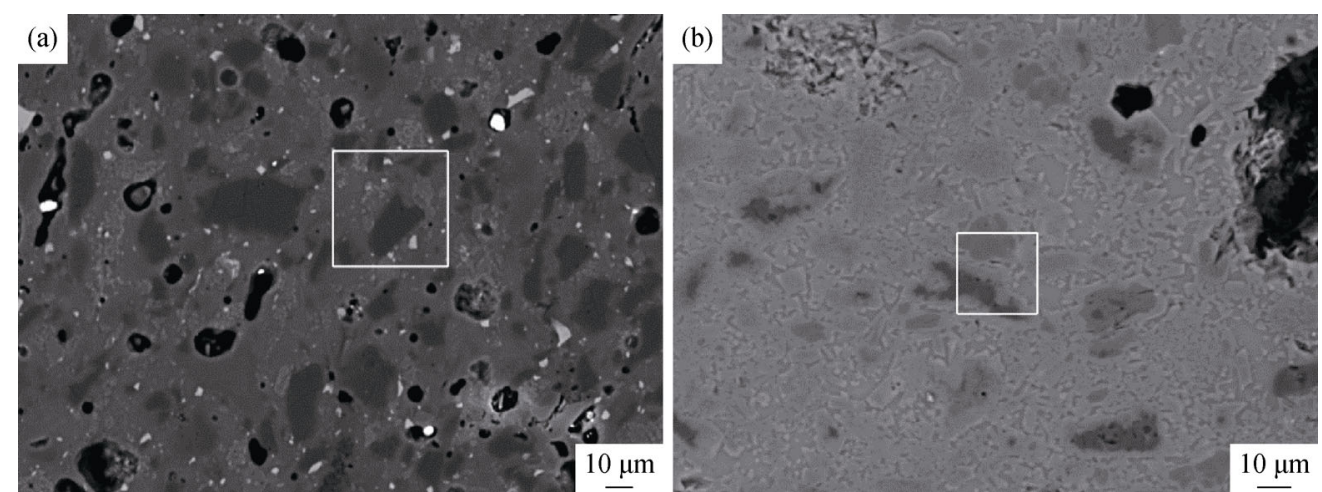

Fig. 2. Surface backscattered electron images of samples A3 (a) and M2 (b).
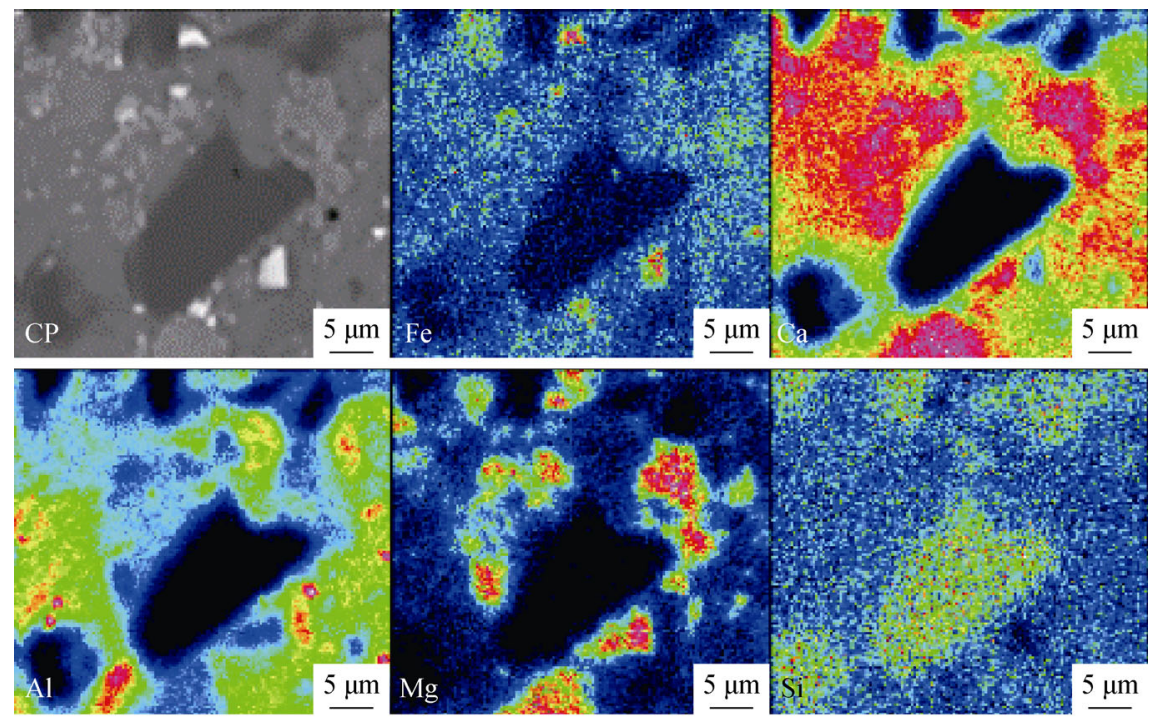

(a) A3

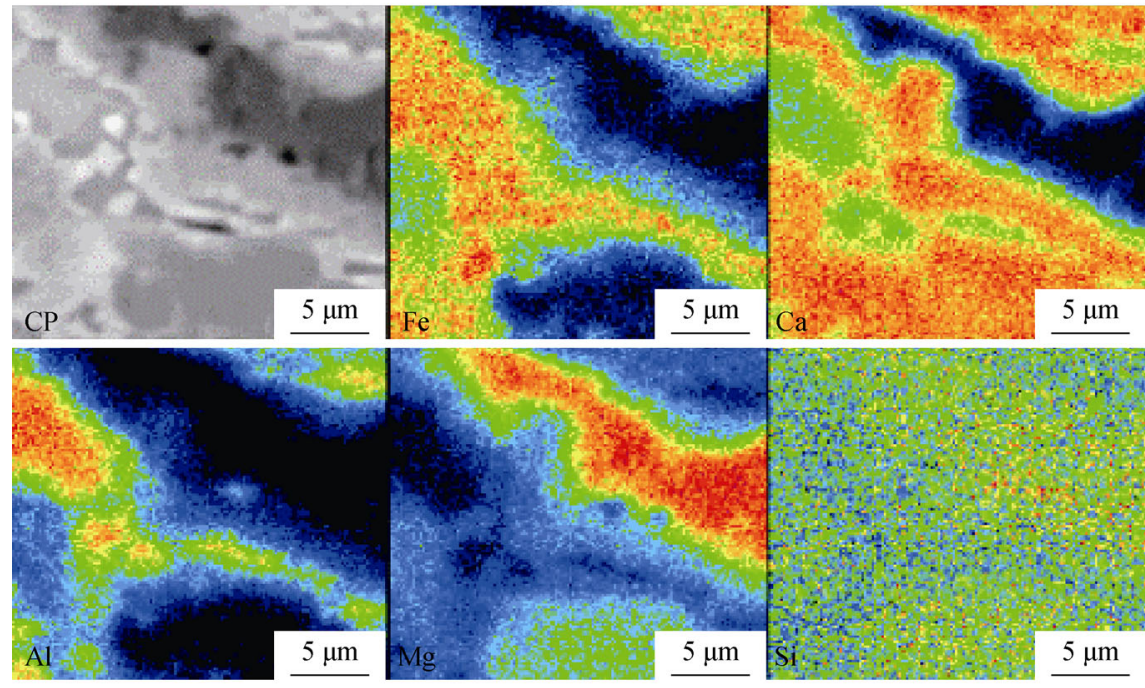

(b) M2

Fig. 3. Surface element scanning images of samples A3 (a) and M2 (b).

The distributions of $\mathrm{Fe}$ and $\mathrm{Ca}$, which were introduced by the steel slag, reflect the degree of interaction between steel slag and clay. The obvious enrichment of these elements suggests that the raw materials of sample A3 were sintered mainly during the firing process, and the vitrification process was not obvious. Note that the area in Fig. 2(b) had 
analogous and inerratic features among the connected phases, inconspicuous boundaries between different areas with similar gray scales, and significant and homogeneous element diffusion, especially for Si (Fig. 3(b)). Thus, the vitrification effect was distinctive, which may benefit the macroscopic performance.

\subsection{Microstructure of steel slag ceramics}

Samples A3 and M2 were selected for SEM observation due to their good bending strength, and the images are shown in Fig. 4. The grain size of M2 was larger than that of A3, and the crystal shapes of M2 were remarkably different

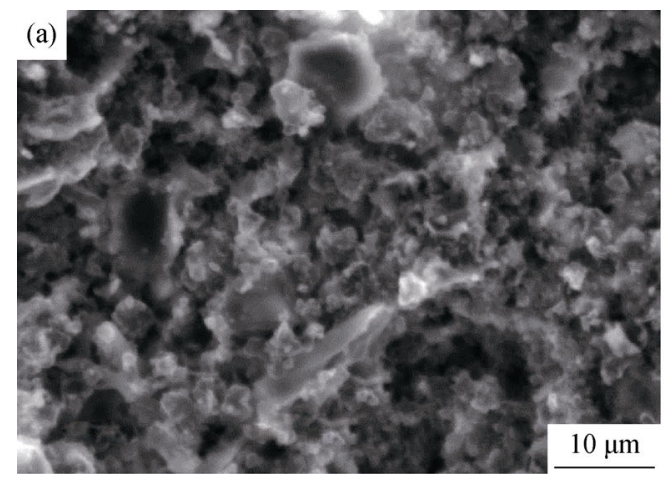

from those of A3. However, the bending strength of M2 was nearly double that of $\mathrm{A} 3$, which is inconsistent with the viewpoint that grain size is the dominant factor in the bending strengths of multicrystalline materials. Hence the degree of vitrification should be considered in this study.

As mentioned above, vitrification may densify and strengthen the ceramics. In sample M2, more vitrification can be observed, and the grains are tightly bound together. In contrast, the structure of A3 is incompact without suitable glassy phases, resulting in easier fracture. In this sense, vitrification is important for the bending strengths of the ceramics.

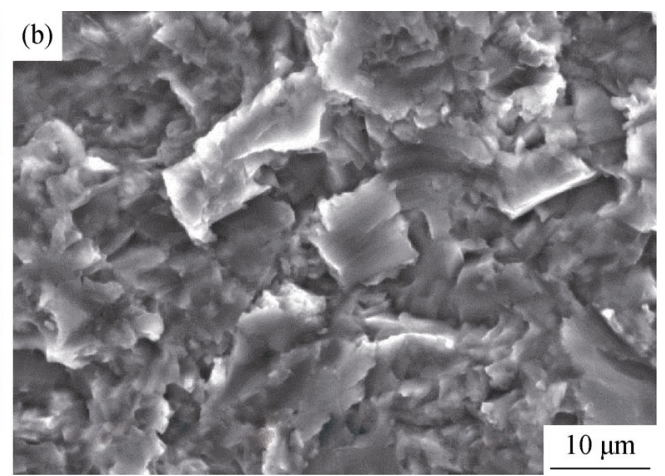

Fig. 4. Microstructural images of samples A3 (a) and M2 (b).

\section{Discussion}

\subsection{Relation between the chemical composition of raw materials and liquefaction and crystallization}

Although the degree of vitrification of sample A3 cannot be determined from the EPMA results, obvious dispersed peaks are observed in the corresponding XRD pattern, indicating the existence of the glassy phase. In contrast, the M group samples tend to crystallize completely. As the two groups of samples belong to different silicate composition systems, the differences in XRD patterns of the two groups are related to their compositions. Vitrification plays an important role in the mechanical properties of ceramics. The glassy phase generated by the vitrification process may splice grains of raw materials and densify the ceramic. Furthermore, new crystal phases appear during cooling after vitrification. This changes the crystal phase composition, which also affects the mechanical properties. Due to the significant effects of vitrification on the ceramics, the role of oxides in the glass melt during vitrification and crystallization should be discussed in detail.

Oxides can be divided into the following three categories according to their functions in glass melts [10-11]: glass-forming oxides, glass-modifying oxides, and intermediate oxides in glass.

Glass-forming oxides are the principal part of the silica melt network; they can form a complete network and increase the viscosity of the melt. The glass-forming oxides are normally $\mathrm{SiO}_{2}, \mathrm{~B}_{2} \mathrm{O}_{3}, \mathrm{P}_{2} \mathrm{O}_{5}$, etc.

Glass-modifying oxides that break up the glass network are known as network modifiers. As the $\mathrm{M}-\mathrm{O}$ bonding ( $\mathrm{M}$ represents the metal ion of the glass-modifying oxide) is ionic with low electric field intensity and easily escaping $\mathrm{O}^{2-}$, modifying oxides provide free oxygen and act as network breakers. Alkali oxides such as $\mathrm{Na}_{2} \mathrm{O}$ and $\mathrm{K}_{2} \mathrm{O}$ along with alkaline earth oxides such as $\mathrm{CaO}$ and $\mathrm{MgO}$ are added to silica glass to lower its viscosity so that it can be worked at points joining the tetrahedra and break up the network, producing oxygen atoms with unshared electrons. The metal ions do not enter the network, but instead remain as metal ions ionically bonded in the network. By filling some of the interstices, these ions promote the crystallization of the glass. On one hand, alkaline earth oxides function as alkali oxides, depolymerizing large tetrahedral bunches and lowering the viscosity; on the other hand, due the higher valence states and smaller ionic radii of alkaline earth oxides, the bonding forces of alkaline earth oxides are stronger, increasing the 
level of accumulation and melt viscosity. Therefore, alkaline earth oxides decrease the viscosity at high temperatures (e.g., $1000^{\circ} \mathrm{C}$ ), but increase the viscosity at lower temperatures. Low viscosity at high temperature favors diffusion, while high viscosity at low temperature favors the ordered arrangement of atoms and slows crystal growth.

Intermediate oxides in glass cannot form a glass network by themselves, but they can join into an existing network. $\mathrm{I}-\mathrm{O}$ bonding (I represents the metal ions of intermediate oxides) with single bonding energies between 251.21 $334.94 \mathrm{~kJ} / \mathrm{mol}$ has a partial covalent character; however, its ionic character is still dominant. The coordination numbers of the metal ions of intermediate oxides are variable; their coordination number is generally six, but can be changed to four after the capture of free oxygen. When the coordination number exceeds six, the metal ions are outside the network, and the oxides function analogous to glass-modifying oxides. When the coordination number changes to four, the metal ions enter the network, and the oxides function as glass-forming oxides. The common intermediate oxides are $\mathrm{Al}_{2} \mathrm{O}_{3}, \mathrm{TiO}_{2}, \mathrm{ZnO}$, etc.

Due to the existence of aluminosilicate (anorthite and augite), the properties of $\mathrm{Al}_{2} \mathrm{O}_{3}$ are much closer to those of glass-forming oxides. Therefore, $\mathrm{Al}_{2} \mathrm{O}_{3}$ could be regarded as a glass-forming oxide. As a result, the content of glass-forming oxides was high in group A (up to $65 \mathrm{wt} \%$ ), while the content in group $\mathrm{M}$ was only about $50 \mathrm{wt} \%-55 \mathrm{wt} \%$. The content of glass-modifying oxides in the A-series was lower than $18 \mathrm{wt} \%$, while the content was nearly $30 \mathrm{wt} \%$ in the M-series. Due to the rather low contents of $\mathrm{Ti}, \mathrm{K}$, and $\mathrm{Na}$ along with their limited effects on mixed systems, the analysis focuses on $\mathrm{Si}, \mathrm{Al}, \mathrm{Mg}, \mathrm{Ca}$, and $\mathrm{Fe}$. The contents of glass-modifying oxides, which reduce viscosity at high temperature, were quite low; therefore, the corresponding melt has high viscosity at high temperature. Considering the high viscosity and the lower firing temperature, crystallization is difficult due to the rapidly increasing viscosity during cooling; thus, the glassy phase is the main phase of the A-series samples after cooling. Moreover, the high viscosity at high temperature makes element diffusion difficult and thus causes local element enrichment conspicuous, leading to the crystallization of augite and diopside and the enrichment of $\mathrm{Mg}, \mathrm{Ca}$, and $\mathrm{Si}$. In contrast, the considerable contents of glass-modifying oxides in the M-series samples leads to low viscosity at high temperature, and an extensive liquid phase exists at about $1200^{\circ} \mathrm{C}$, as indicated by the EPMA images (Fig. 3(b)). These results imply that the M-series adobes may deform easily during firing. After cooling, the extensive liquid phase transforms into crystalline and glassy phases; these phases fill the holes and densify the ceramic, resulting in the excellent properties of the corresponding samples.

\subsection{Relation between the phase composition of the raw materials and liquefaction and crystallization}

As mentioned above, composition, especially the content of glass-modifying oxides, significantly affects firing and mechanical properties; however, the effects of the phase compositions of raw materials have not been previously discussed in detail, even though these effects should not be ignored during firing.

Yang et al. [12] used $\mathrm{CaCO}_{3}, \mathrm{MgO}$, and $\mathrm{SiO}_{2}$ (analytical reagent) with congruent melting at a mole proportion of 1:1:2 to synthesize diopside at different temperatures $\left(1050-1400^{\circ} \mathrm{C}\right)$. Their experiment demonstrated that diopside generation begins above $1350^{\circ} \mathrm{C}$, and the raw materials react completely to form diopside at $1400^{\circ} \mathrm{C}$ [12]. The compositions of the samples in these experiments $\left(25.87 \mathrm{wt} \% \mathrm{CaO}, 18.61 \mathrm{wt} \% \mathrm{MgO}\right.$, and $\left.55.52 \mathrm{wt} \% \mathrm{SiO}_{2}\right)$ belonged to the $\mathrm{CaO}-\mathrm{MgO}-\mathrm{SiO}_{2}$ system. However, the parent glass, which is the glass-ceramic precursor and has a similar chemical composition, nucleates and crystallizes below $1000^{\circ} \mathrm{C}$, also with diopside as the dominant crystal phase [13-15]. The essential difference between Yang's [12] diopside synthesis and glass-ceramic production is that the crystal phase composition is different before crystallization in the entire system. In Yang's experiment, the raw materials were crystals with ionic bonds $(\mathrm{CaO}$ and $\mathrm{MgO})$ and ionic-covalent mixed bonds $\left(\mathrm{SiO}_{2}\right)$. However, in the glass-ceramic synthesis, diopside was generated from parent glass with controlled nucleation and crystallization conditions. The relation between the crystal phases of raw materials and heat treatment as well as high temperature performance is rather apparent.

The bond energies of the ionic bonds in $\mathrm{MgO}$ and $\mathrm{CaO}$ and the ionic-covalent mixed bonds in $\mathrm{Al}_{2} \mathrm{O}_{3}$ and $\mathrm{SiO}_{2}$ are quite strong. According to the phase diagrams of the $\mathrm{CaO}-\mathrm{MgO}-\mathrm{SiO}_{2}$ and $\mathrm{CaO}-\mathrm{MgO}-\mathrm{Al}_{2} \mathrm{O}_{3}-\mathrm{SiO}_{2}$ systems [6], the lowest liquidus temperature is higher than $1350^{\circ} \mathrm{C}$ in the systems consisting of simple oxides; therefore, a specified volume of liquid exists at rather high temperatures. This liquid can be referred to as a silica melt or glass melt, which is related to vitrification.

Glass is popularly regarded as the solid product of cooling a non-crystallizing liquid [16]. Vitrification in the cooling of melts is commonly interpreted as the transformation of a thermodynamically (meta-) stable equilibrium system into a frozen-in, thermodynamically non-equilibrium system. 
The glass is quickly formed under the great cooling rate. Thus, in a first approximation, the transformation is assumed to proceed at a well-defined temperature, the glass-transition temperature, $T_{\mathrm{g}}$ [17]; this is one of the most important characterization parameters of the glassy state [18]. $T_{\mathrm{g}}$ is a function of viscosity; $T_{\mathrm{g}}$ decreases with decreasing viscosity [15]. For silica glass, $T_{\mathrm{g}}$ is generally lower than $1000^{\circ} \mathrm{C}$ [19]. When the temperature is higher than $T_{\mathrm{g}}$, solid glass will transform into an undercooling melt, and liquid begins to form, dramatically changing the properties of the melt. As mentioned above, a proper amount and a suitable viscosity of liquid are beneficial for crystallization and densification.

Dispersed peaks were widespread in the XRD patterns of steel slag [20], demonstrating that a glassy phase is originally present in steel slag; hence, an extensive liquid phase is generated at low temperatures. Due to the presence of glassy phases in steel slag and crystalline phases in all the ceramic raw materials, the firing temperature of steel slag ceramic is lower than the traditional firing temperature, but higher than that of glass-ceramics. Because of the less content of the glassy phase in steel slag, the firing temperatures of steel ceramics are higher than that of glass-ceramics.

\section{Conclusions}

(1) As a main raw material for A-series and M-series ceramic tiles, steel slag performed well, resulting in high bending strengths of $53.47 \mathrm{MPa}$ and $99.84 \mathrm{MPa}$, respectively. This study provides a new approach for the extensive recycling of steel slag, as the achieved bending strengths exceed the Chinese national regulation for residential porcelain tiles $(\geq 35 \mathrm{MPa})$.

(2) The XRD patterns of the samples show that the dominant crystal phases of the A-series samples are anorthite, $\alpha$-quartz, and magnetite, which are the crystal phases of the raw materials with the exception of anorthite. The dominant crystal phases of the M-series samples are augite, diopside, or pyroxene solid solutions, which are all newly generated crystal phases.

(3) The XRD patterns, backscattered images, and element scanning images of the typical samples A3 and M2 indicate that the raw materials of A3 were mainly sintered, while vitrification was insufficient. In contrast, the effects of vitrification are distinctive in M2. Chemical and phase compositions both play pivotal roles in sintering, vitrification, and crystallization processes. Chemical composition has a significant impact on liquid viscosity at high temperature, element diffusion, and crystallization (dominant crystal phases).
Phase composition (glassy phase) is related to liquid generation and further vitrification during firing. The existence of glassy phases in the raw materials may promote liquid generation at low temperatures, and good vitrification and crystallization improve macroscopic performance.

(4) The crystal phases of steel slag ceramics belong to the $\mathrm{CaO}-\mathrm{Al}_{2} \mathrm{O}_{3}-\mathrm{SiO}_{2}$ or $\mathrm{CaO}-\mathrm{MgO}-\mathrm{SiO}_{2}$ systems. Due to the considerable contents of glass-modified oxides and glassy phases, extensive liquid phases with low viscosities are generated at rather low temperatures during ceramic firing, leading to a low firing temperature and a small range of firing temperatures for the steel slag ceramics. However, the adobe distorts easily, making the accuracy control of the firing process particularly important for steel slag ceramic production.

Open Access This article is distributed under the terms of the Creative Commons Attribution License which permits any use, distribution, and reproduction in any medium, provided the original author(s) and the source are credited.

\section{References}

[1] C.B. Yi, D. Ou Yang, and L.L. Lu, The study on feasibility of steel slag abrasive used in shot peening derusting in hull, Surf. Technol., 39(2010), No. 4, p. 91.

[2] Y. Zhang, J. Zhang, T.Y. Zhang, Y.M. Liu, and Z.B. Han, Analysis of steel slag treatment technology and waste heat recovery technology, China Metall., 24(2014), No. 8, p. 33.

[3] X. Wang, Recovery and utilization of steel-making slag, Wuhan Iron Steel Corp. Technol., 44(2006), No. 5, p. 51.

[4] X.H. Ma and J.C. Chen, Preparing high strength hollow block using steel slag, Fly Ash Compr. Utiliz., (2004), No. 5, p. 42.

[5] M. Zhang, M.L. Cao, J.C. Chen, and X.H. Ma, Preparation of small-sized hollow brick from electric stove slag mixed with expanded pearlite, Non-metallic Mines, 27(2004), No. 4, p. 21.

[6] J. Wang, Slag Atlas, The Metallurgical Industry Press, Beijing, 1989, p. 113.

[7] Y.J. Liu, X.F. Wang, and L.Y. Cao, Research on high strength mullite based microcrystalline ceramics thin tiles, $J$. Synth. Cryst., 39(2010), p. 156.

[8] E. Sánchez, J. García-Ten, V. Sanz, and A. Moreno, Porcelain tile: almost 30 years of steady scientific-technological evolution, Ceram. Int., 36(2010), No. 3, p. 831.

[9] Y.S. Li and N.Y. Liu, Unglazed porcelainized tile characterization, China Ceram., 33(1997), No. 1, p. 12.

[10] W.F. Smith and J. Hashemi, Foundations of Materials Science and Engineering, 4th Ed., McGraw-Hill, New York, 2005, p. 21.

[11] Y.Z. Zhao, Glass Technology, Chemical Industry Press, Beijing, 2006, p. 20. 
[12] Z.J. Yang, H. Yang, X. Xue, and P.N. Duan, Study on diopside synthesis and its photocatalysis. J. Mater. Metall., 9(2010), No. 2, p. 101.

[13] A. Karamanov and M. Pelino, Sinter-crystallisation in the diopside-albite system: Part I. Formation of induced crystallisation porosity, J. Eur. Ceram. Soc., 26(2006), No. 13, p. 2511.

[14] A. Karamanov and M. Pelino, Induced crystallization porosity and properties of sintereds diopside and wollastonite glass-ceramics, J. Eur. Ceram. Soc., 28(2008), No. 3, p. 555.

[15] A. Goel, E.R. Shaaban, J.B. Oliveira, M.A. Sá, M.J. Pascual, and J.M.F. Ferreira, Sintering behavior and devitrification kinetics of iron containing clinopyroxene based magnetic glass-ceramics, Solid State Ionics, 186(2011), No. 1, p. 59.

[16] C.A. Angell, The glass transition, Curr. Opin. Solid State
Mater. Sci., 1(1996), No. 4, p. 578.

[17] T.V. Tropin, J.W.P. Schmelzer, and C. Schick, On the dependence of the properties of glasses on cooling and heating rates: I. Entropy, entropy production, and glass transition temperature, J. Non Crystall. Solids, 357(2011), No. 4, p. 1291.

[18] L. Tichý and H. Tichá, Covalent bond approach to the glass-transition temperature of chalcogenide glasses, J. Non Crystall. Solids, 189(1995), No. 1-2, p. 141.

[19] S. Webb and R. Knoche, The glass-transition, structural relaxation and shear viscosity of silicate melts, Chem. Geol., 128(1996), No. 1-4, p. 165.

[20] X.B. Ai, Research on Ceramic of $\mathrm{SiO}_{2}-\mathrm{CaO}$ System from Steel Slag [Dissertation], University of Science and Technology Beijing, Beijing, 2013, p. 45. 